\title{
A case of late-onset capsular block syndrome and its surgical treatment
}

\author{
Um caso de síndrome de bloqueio capsular tardio e uma \\ abordagem cirúrgica
}

Vinicius Campos Bergamo', Luis Filipe Nakayama1', Verônica Haysa Yamada', Fábio Iglesias Marujo

1. Department of Ophthalmology, Escola Paulista de Medicina, Universidade Federal de São Paulo, São Paulo, SP, Brazil.

\begin{abstract}
Capsular block syndrome is a rare complication of phacoemulsification surgery with continuous curvilinear capsulorhexis and intraocular lens implantation. Here, we report a case of very late-onset capsular block syndrome that developed 13 years after cataract extraction and present the surgical approach used for its successful treatment.
\end{abstract}

Keywords: Phacoemulsification/adverse effects; Lens implantation, intraocular/adverse effects; Cataract extraction/adverse effects; Lens, capsule; Capsulorhexis

RESUMO | Síndrome do bloqueio capsular é uma complicação incomum da cirurgia de facoemulsificação com capsulorrexis curvilínea contínua e implante de lente intraocular. Nós relatamos um caso de síndrome de bloqueio capsular de início tardio que se desenvolveu após 13 anos da extração da catarata e apresenta a abordagem cirúrgica utilizada para o sucesso do tratamento.

Descritores: Facoemulsificação/efeitos adversos; Implante de lente intraocular/efeitos adversos; Extração de catarata/efeitos adversos; Cápsula do cristalino; Capsulorrexe

\section{INTRODUCTION}

Late-onset capsular block syndrome (CBS) is a rare condition that may occur after phacoemulsification cataract surgery with continuous curvilinear capsulorhexis and intraocular lens (IOL) implantation inside the capsular bag ${ }^{(1,2)}$. Opaque milky-white material accumulates between the posterior face of the $\mathrm{IOL}$ and the posterior lens capsule leading to capsular bag distention and visual acuity disturbances. The material originates pri-

Submitted for publication: March 26, 2018

Accepted for publication: September 21, 2018

Funding: No specific financial support was available for this study.

Disclosure of potential conflicts of interest: None of the authors have potential conflicts of interest to disclose.

Corresponding author: Vinicius Campos Bergamo

Rua Napoleão de Barros, 1098/31 - São Paulo - SP - 04024-003 - Brazil

E-mail: viniciusbergamo.epm@gmail.com marily from residual epithelial lens cells, but its exact pathogenesis is yet to be elucidated ${ }^{(3)}$.

Three different types of CBS exist according to Miyake et al. An intraoperative capsular block occurs when balance saline solution accumulates between the nucleus and the posterior bag capsule during the hydro-dissection, likely leading to capsular breaks and nucleus dislocation to the vitreous cavity. An early postoperative capsular block occurs during the first 2 weeks after surgery, mainly because of the accumulation of viscoelastic material between the $\mathrm{IOL}$ and the posterior bag capsule. Late-onset capsular block occurs months or years after the surgery because of proliferation and metaplasia of residual epithelial cells that form the characteristic milky-white material ${ }^{(4)}$.

Late CBS occurs about 3.8 years after cataract surgery, although some case reports have described onsets as late as 12 years after the procedure ${ }^{(1,5)}$.

The major treatment option is based on posterior capsulotomy with neodymium yttrium aluminum garnet laser ( $\mathrm{Nd}$ : YAG) directed at the posterior lens capsule that creates a path and leads to material leakage into the vitreous cavity and subsequent visual acuity (VA) improvement. Laser capsulotomy with Nd: YAG is the best currently used treatment option because of its few collateral effects, low complication rates, and increased convenience.

However, rare cases may need a surgical approach to remove the material ${ }^{(2,6)}$ when laser capsulotomy is impossible and the opacity leads to decreased visual acuity ${ }^{(3)}$.

\section{CASE REPORT}

A 63-year-old woman with bilateral and separate uncomplicated phacoemulsification surgeries performed 13 years ago presented with decreased visual acuity in her right eye for a year without progression. She did 
not complain of ocular pain, redness, or any associated symptoms.

On ophthalmological examination, she had an uncorrected visual acuity of counting fingers at $2 \mathrm{~m}$ in the right eye and $0.6(\log M A R)$ in the left eye. After -1.0-1.0 at 150 , the best corrected visual acuity (BCVA) improved to 1.0 (logMAR) in the right eye; after $-0.25-1.25$ at 25, the BCVA improved to 0.1 (logMAR) in the left eye.

The slit-lamp anterior biomicroscopical examination of the right eye revealed a nonhyperemic conjunctiva; clear cornea, without anterior chamber cells; a topic IOL; and opaque material between the lens and the posterior capsule. Binocular indirect ophthalmoscopy to evaluate the posterior pole was impossible because of media opacities (Figures 1-2). The intraocular pressure measured at 13:00 hours using Goldmann tonometry was $14 \mathrm{mmHg}$ in the right eye and $12 \mathrm{mmHg}$ in the left eye.

Ultrasound evaluation showed an attached retina without significant findings in the vitreous cavity of the right eye.

The anterior segment of the same eye was also evaluated using anterior segment optical coherence tomography (Visante ${ }^{\circledR}$ Zeiss). Hyper-reflective material was found between the lens and posterior capsule, which had led to capsular distention. As the capsular bag was complete, we confirmed the diagnosis of CBS (Figure 3).

We attempted an Nd: YAG capsulotomy twice, but failed because of media opacities. We then proposed a surgical approach to remove the milky-white material and maintain the $\mathrm{lOL}$ under topical anesthesia.

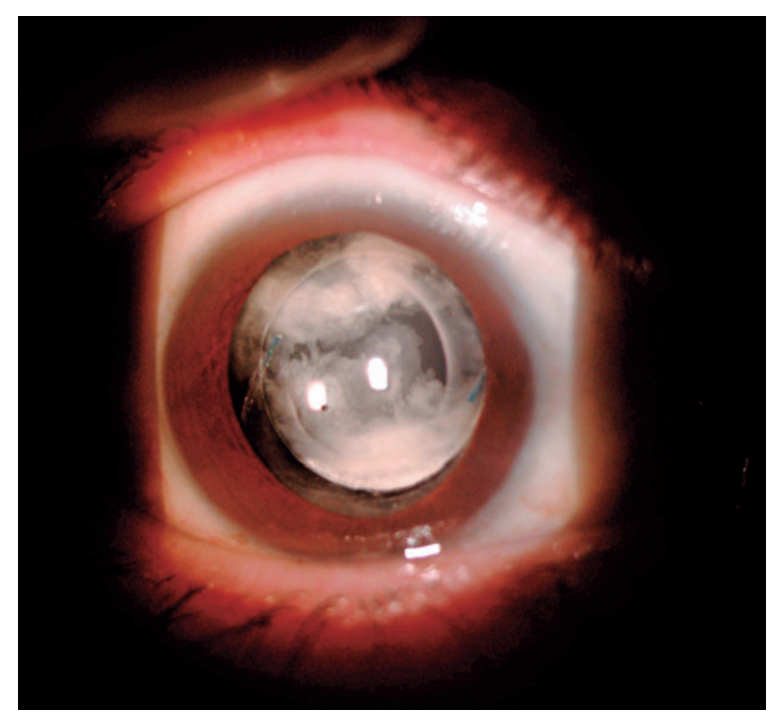

Figure 1. OD slit lamp photograph showing the milky-white material behind the IOL.

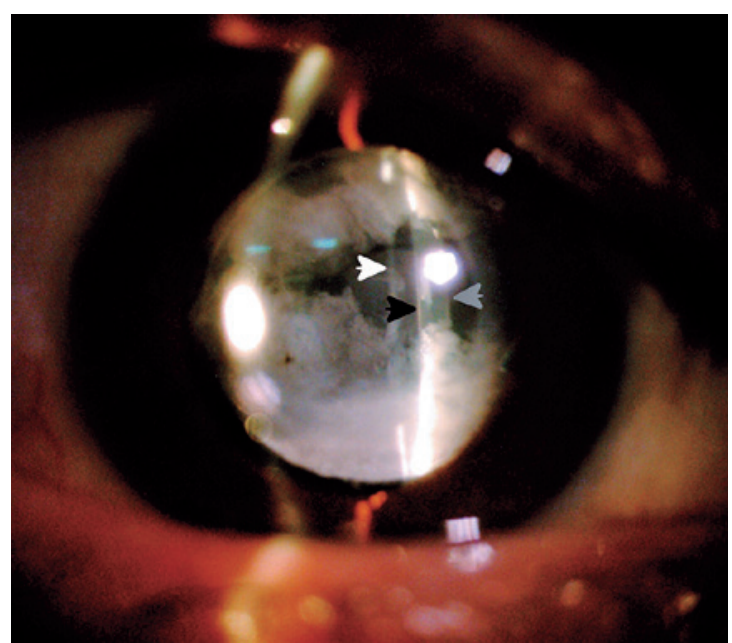

Figure 2. OD slit-lamp photograph showing the slit-lamp light over the anterior intraocular lens surface (white arrow), the slit-lamp light over the posterior intraocular lens surface (black arrow), and the slit-lamp light over the posterior capsule (gray arrow)

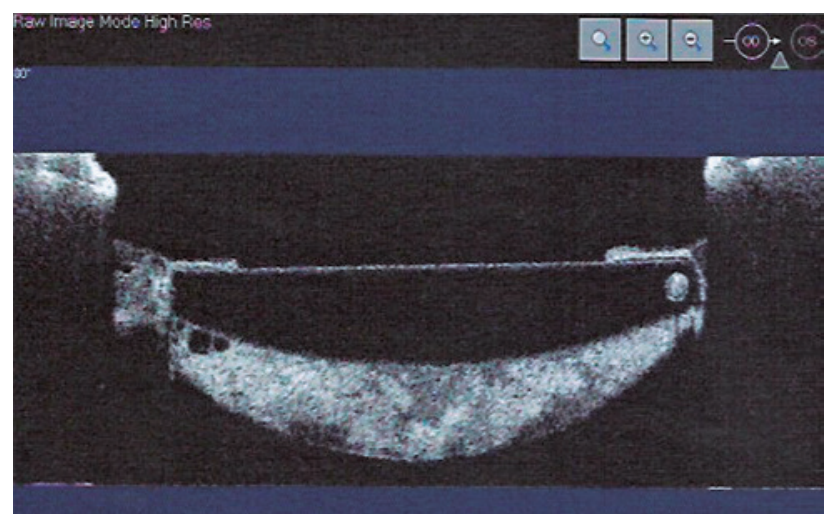

Figure 3. $O D$ anterior segment optical coherence tomography showing a posterior capsular distention and a hyper-reflective material inside the capsular bag.

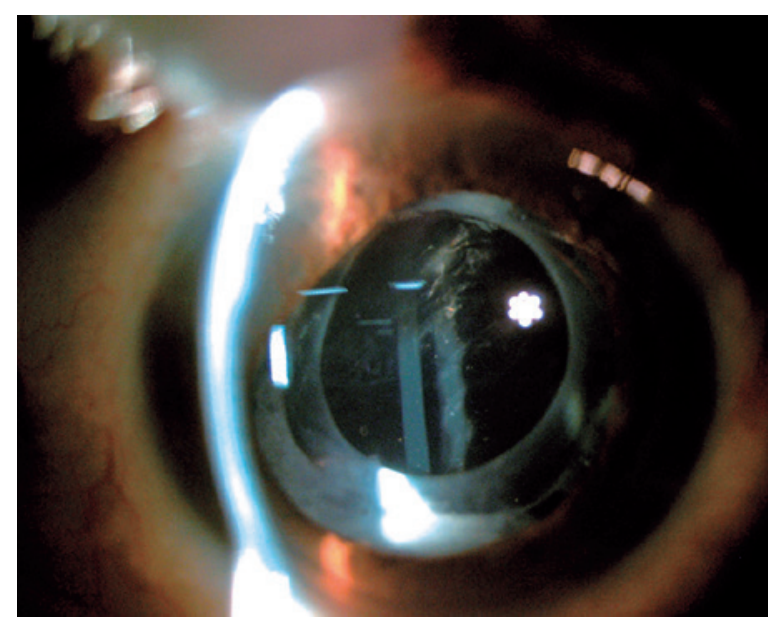

Figure 4. OD postoperative slit lamp photograph showing clear, intact, and wrinkled posterior capsule with no sign of intracapsular material. 
The primary incision was made following the threeplanes technique using a $2.75-\mathrm{mm}$ incision blade and the secondary incision was made using a straight blade at $15^{\circ}$.

First, we tried rotating the $\mathrm{IOL}$ inside the capsular bag to mobilize the material, but we could not achieve the rotation because of the fibrosis between the anterior bag capsule and the IOL. We then performed a viscodissection by injecting a dispersive viscoelastic material between the $\mathrm{IOL}$ and the posterior bag capsule to successfully mobilize the milky-white material to the anterior chamber, from where it was aspirated using a coaxial irrigation/aspiration hand-piece. The residual viscoelastic material from behind the IOL was also removed.

Histopathological and microbiological analyses of the aspirated material showed no bacterial growth.

At the first postoperative follow-up visit, the patient presented with a clear cornea and a topic and centered IOL without any material behind it. We could observe a clear, intact, and wrinkled posterior capsule (Figure 4) and a BCVA of 0.2 (logMAR).

At the 30th postoperative evaluation, the patient had no complications, and the BCVA remained at 0.2 (logMAR). Nevertheless, we performed a posterior lens capsulotomy with Nd: YAG laser to prevent future recurrences.

The intraocular pressure showed no significant variations during the postoperative follow-ups.

\section{DISCUSSION}

CBS is a rare complication related to phacoemulsification surgery with continuous curvilinear capsulorrhexis (CCC). It is identified by the presence of an intracapsular fluid bag between the $\mathrm{IOL}$ and the posterior capsule $\mathrm{e}^{(1,2)}$.

In our presenting patient, CBS had developed 13 years after the phacoemulsification surgery (the longest reported interval to the best of our knowledge), classifying it as type-3 $\mathrm{CBS}^{(1,3,5-8)}$.

Our initial failure to treat the eye with Nd: YAG capsulotomy may be explained by the long disease progres- sion, which allowed for the development of a compact and thermic energy laser-resistant material that interrupted the path of the laser to the posterior lens capsule.

We opted for a surgical approach, although we found no reports on an exact surgical technique that is to be used after Nd: YAG treatment failure. The surgery was performed by injecting dispersive viscoelastic solution to successfully mobilize the milky-white material to the anterior chamber, from where it was aspirated using a coaxial irrigation/aspiration hand-piece. There were no complications or adverse events during the procedure or the postoperative follow-up period, proving the safety of this procedure.

In our presenting patient, microbiological analysis of the milky-white material was negative, although a study reported cases positive for Propionibacterium acnes ${ }^{(7)}$.

Overall, this is the first case of late-onset CBB, which had developed 13 years after a phacoemulsification surgery, that was surgically treated through the anterior chamber using a coaxial irrigation/aspiration hand-piece and a dispersive viscoelastic injection.

\section{REFERENCES}

1. Zhu XJ, Zhang KK, Yang J, Ye HF, Lu Y. Scheimpflug imaging of ultra-late postoperative capsular block syndrome. Eye (Lond). 2014;28(7):900-4.

2. Yang MK, Wee WR, Kwon JW, Han YK. Anterior chamber depth and refractive change in late postoperative capsular bag distension syndrome: a retrospective analysis. PLoS One. 2015;10(4):e0125895.

3. Huang Y, Ye Z, Li H, Li Z. Outcome of surgical treatment in late-onset capsular block syndrome. J Ophthalmol. 2017;2017:1847179.

4. Miyake K, Ota I, Ichihashi S, Miyake S, Tanaka Y, Terasaki H. New classification of capsular block syndrome. J Cataract Refract Surg. 1998;24(9):1230-4.

5. Sia DI, Gilhotra J. Late-onset capsular block syndrome. Int Ophthalmol. 2012;32(5):455-7.

6. Morgan-Warren P, Manna A. Late-onset capsular bag distension syndrome following cataract surgery. JRSM Short Rep. 2011;2(6):53.

7. Rana $M$, Jiang L, llango B, Yang YC. Late-onset capsular block syndrome: unusually delayed presentation. Case Rep Ophthalmol. 2013;4(3):299-302.

8. Vélez M, Velásquez LF, Rojas S, Montoya L, Zuluaga K, Balparda K. Capsular block syndrome: a case report and literature review. Clin Ophthalmol. 2014;8:1507-13. 